\title{
The Interorganizational Relationships Process: An Asset Orchestration Mechanisms Perspective in an SME Context
}

\author{
Claudia Pelletier \\ Université du Québec à Trois-Rivières \\ claudia.pelletier@uqtr.ca
}

\author{
Dragos Vieru \\ Université du Québec (TELUQ) \\ dragos.vieru@teluq.ca
}

\author{
Anne-Marie Croteau \\ Concordia University \\ anne-marie.croteau@,concordia.ca
}

\begin{abstract}
This exploratory study analyzes the collaborative efforts between two small and medium enterprises (SMEs) engaged in an interorganizational relationship (IOR) aimed at developing cospecialized and complementary assets through coordinating mechanisms. Despite the richness of the literature on IOR, less is known about the mechanisms that trigger and affect collaborative efforts during an IOR process. We adopt a qualitative and processual approach and draw on the concepts of assets orchestration mechanisms, surface structures and deep structures to propose a conceptual framework. We conjecture that the connection between surface structures and deep structures of the IOR process is facilitated by three specific mechanisms: allocating resources, structuring resources and coordinating resources. Our single case data analysis suggests that IOR efforts work well across organizational boundaries between business partners thanks to the assets orchestration mechanisms and when shared vision and artefacts are translated into shared processes and practices.
\end{abstract}

\section{Introduction}

In the traditional context of interorganizational relationship (IOR), the focus is usually on the challenges encountered by the partners with a special attention paid to the structures they put in place, the processes they perform, the technologies they use to gain some of the advantages of IOR, and how those advantages outweigh the disadvantages. In other words, most research on IOR generally relies on transactional, structural, and technical interfaces shared by the partners $[1,2]$ without a real concern about the dynamics and the processes by which jointly profit generation is realized [3]. However, in a context characterized by an increased complexity and a growing use of information technology (IT) [4, 5],
IORs are successful when innovative and collaborative firms avoid the trap of overlaying new processes on existing structures [6]. Indeed, it is shown that formal structures alone are insufficient to ensure success in an interorganizational context [7, 8]. Identifying and understanding the appropriate mechanisms for balancing tensions between autonomy and synergy between the partners is still an understudied topic in the information systems (IS) literature $[9,10]$.

The IS literature suggests that open IT standards and universal applications-based knowledge generated in the context of traditional IORs, such as electronic data interchange (EDI) or supply chain management, is generally insufficient for the study of this phenomenon in the $21^{\text {st }}$ century [7, 11]. Thus, this research aims at understanding how each relationship is built, developed, and maintained by business partners, and what mechanisms are privileged in order to make those IORs as beneficial as initially planned. Croteau et al. (2008) posit that business partners need to have well-aligned mechanisms for processing information between their firms. Not only do they need to agree on the information that should be shared, they also have to coordinate the mechanisms to implement the process of sharing information. In order to realize the objectives pursued by the partners, specific efforts in managing and organizing firm resources through an adequate coordination process must be implemented $[10,12]$.

Nevertheless, despite the interest of extant studies on IOR, less is known about the mechanisms that trigger and affect the contextualized efforts during an interorganizational collaborative process [7, 13]. Moreover, when partners are not bound by hierarchy and authority-based relationships, it becomes even more difficult to understand the nature of their exchange $[5,9]$. The same complexity applies to the specific mechanisms by which business partners align with each other to improve their processes, to adopt more sophisticated practices, and to share pertinent information $[14,15]$. 
This exploratory study adopts a perspective that takes into consideration how internal processes of each business partner at different levels of analysis shape each other $[16,17]$. More specifically, it aims at identifying the specific mechanisms at work and providing a better understanding of the recursive nature of the structures and social dimensions involved in the IOR context [18]. To do so, we explore an IOR process by using the concept of asset orchestration mechanisms $[19,20]$. Derived from an extended resource-based view (RBV), this concept proposes a specific terminology about managing and coordinating firm resources and addresses the complexity of interorganizational knowledge sharing $[5,6]$.

The concept of asset orchestration mechanisms highlights more clearly how each business partner adapts and transforms its basic resources (surface structures - i.e. shared strategic vision and artefacts) into more complex and sophisticated resources (deep structures - i.e. shared processes and practices) in order to build and maintain a successful IOR with the other partners [21, 22].

Based on the above argumentation, we propose the following research question:

How do asset orchestration mechanisms interact to enable an interorganizational relationships process between the involved partners?

Drawing on the IOR literature, this study proposes a conceptual framework that suggests that the surface structures and the deep structures of the IOR process are connected by three specific mechanisms: allocating resources, structuring resources and coordinating resources. These mechanisms derived from the asset orchestration concept do not just have to adapt to each other [19], they also provide more coordination efficacy through formal and informal structures [9], which is often achieved through necessary tradeoffs agreed among business partners [10].

To validate our framework, we assess the IOR process of a small and medium enterprise (SME) specialized in web surveys and interactive voice response services. We examine how the firm's IOR process, structures, and activities aligned and integrated with those of their main business partner by using the lens of the asset orchestration concept. Resulting from an effort of mechanism-based theorizing [28], the main contribution of this exploratory study is to provide a valid conceptual tool for better understanding an IOR process in a context of collaborative exchanges [4].

\section{Theoretical background}

\subsection{Interorganizational relationships processes}

The development of IORs is itself an important strategic decision [23, 24]. Organizations consider having successful relationships with other firms when they can tap into new resources, reach economies of scale, share risks and costs, or gain access to a foreign market.

IORs are made of transactions, flows, and linkages that occur over a relatively long period of time between at least two organizations [25]. Firms create IORs in order to achieve goals that each firm would otherwise not easily be able to attain when acting alone [26]. As such, IORs allow firms to combine resources and share knowledge and risks, optimize assets use, increase market power, maximize their ability to offer attractive products and services, or capitalize on opportunities for organizational learning [8].

With or without technology-based activities, those advantages are often not visible or definable at the beginning of the relationship [24, 27]. However, the decision to undertake these relationships is often based on multiple factors or contingencies where business partners will often weigh the pros and cons of each relationship, and each firm will have its own ultimate deciding factors that lead to the start of the relationship [25].

Most theories on IORs are either based on an economic rationale or on a behavioral perspective [8]. Those that fall under the economic rationale are the transaction cost economics, the resource dependency and strategic choice, whereas the stakeholder theory, learning theory and institutional theory are based on the behavioral school of thought. Each of these theories has several streams of research that provide a piece of the puzzle when it comes to deciphering the why's and how's of IORs.

We notice however that the studies on IORs are often organized around the advantages of IORs. They also look at how business partners mitigate emerging relationship problems through the structures they put in place, the processes they perform, or the technologies they use. Yet, a number of challenges hinder the achievement of successful [8]. These are, just to name a few, the loss of proprietary information, difficulties to manage financial and organizational risks, the increased risk of becoming dependent on a partner, the partial loss of decision autonomy, the potential culture clash and the loss of organizational flexibility. These difficulties are all potential worries that need to be carefully planned for 
at the outset of any IOR [8]. Therefore, in addition to the need of understanding how these elements can be organized in each firm as well as between them [9, 10], IOR maintenance requires careful planning of future contingencies and changing factors as well as mechanisms that adapt to the changes in the relationship itself $[19,28]$.

\subsection{Deep structures}

Organizational structures in a formal arrangement do not always guarantee better performance [29]. In an interorganizational context, these structures may be configured in different ways [1]. The IOR literature shows that relationships in an interorganizational context have been studied from two main perspectives: 1) complementarity and 2) recursivity.

The complementarity perspective adopts a linear study of the IORs process [7] and researchers in this line of thought usually focus on the description of resources, transactions, and structures [11]. Even if a number of studies focus on contingencies and systems integration $[30,31]$, collaborative structures $[1,15]$, or on the maturity state of the IORs $[32,33]$, these studies have two aspects in common. Firstly, they do not clearly identify the mechanisms that underlie the realized processes. Secondly, they underscore a dominant evolution mode of organizational changes that can be illustrated through linear mechanisms such as variation, selection, and retention [16].

Thus, this line of research is preoccupied with what is called surface structures [34], which can be defined in an IOR context as a set of organizational decisions and processes that facilitate the exchanges between both partners. Surface structures contain two main components which are the different IT-artefacts that are compatible in terms of requirements such as data and communication protocols, as well as a the shared vision about the required interfaces to collaborate [2]. We consider that the complementary perspective corresponds to the first level of the IOR process where the decisions are made through shared visions and that the processes are implemented with the help of shared IT-artefacts.

The recusivity perspective focuses on in-depth analyses of the structures at all levels of the IOR process with a particular attention to the challenges related to the processes of sharing knowledge and distribution of power and sharing practices between partners $[13,35]$. Thus, the authors of these studies concentrate their attention on what is called deep structures, which are defined as "continually recurring processes and patterns that underlie and guide surface, observable events and actions" [18] (p.758). The contributions of these studies are: 1) the identification of the structures that trigger and affect the contextualized efforts during an interorganizational collaborative process and that are materialized thanks to the social relations; and 2) the shared practices and values that are put in place.

The recursivity perspective is preoccupied with the study of the recursive nature that characterizes interaction among the deep structures but does not specifically analyze the relational mechanisms with the surface structures that are required to make an IOR process successful.

The complementarity perspective does not cover the entire IOR process either, since it does not take into consideration the core beliefs, values, and daily practices necessary to the IOR process. This perspective does not explain how the deeper surfaces interrelate with the surface structures $[34,36]$.

Therefore, a different lens than those two perspectives is required to better understand how a successful IOR happens, and most importantly how surface and deeper surfaces relate to each other. Unfortunately, these two perspectives do not capture the heavy commitment that is required from all business partners involved as well as the underexplored mechanisms required in the (re)definition of the concerned processes and practices $[12,37]$.

\subsection{Asset orchestration mechanisms}

In an IOR context, we found that an important number of studies focus more on content and technological fit rather than how the firms concretely orchestrate their resources and capabilities [20], organize their respective activities to produce outcomes [10], or make the required efforts to improve their social interactions [18]. This stream of the literature does not explain how deep structures (i.e. processes and practices) interrelate with surface structures (i.e. shared IT artefacts and vision) [2, 7].

Despite the interest in analyzing the antecedents, impacts, and consequences of the adopted systems and technologies in an IOR context [11], identification of the mechanisms used in an IOR process is now an additional criterion to be considered by IOR researchers $[4,24]$. In this regard, the usefulness of the asset orchestration concept is pertinent because it helps in explicitly addressing how managerial actions can contribute to adapt and change the organizational structures and resources required between two partners engaged in an economic activity [19].

Asset orchestration is a dynamic approach that goes beyond the classic value, rarity, inimitability, and non-substitutability characteristics of the classic 
resource based-view (RBV) [12, 37]. Thus, asset orchestration mechanisms in an IOR context are defined as "shared capabilities and organizational routines that can enable firms to access the resources and capabilities of other partners [...] to permit transfer, recombination and/or creation of knowledge" [19] (p. 69). As such, the attention is redirected on the "underexplored processes (i.e., the "black box") that lie between resources" to explain how these resources can be managed by both partners to create superior value [12] (p. 288).

The asset orchestration concept provides a practical perspective to delve into the deeper structures of the IOR process in many ways. First, it offers a dynamic framework to study a processual and complex phenomenon that is constantly evolving [11], within which partners coexist and share knowledge [14], and coevolve in a network mode characterized by a system-level goal [5]. Second, it enables a more accurate identification of the mechanisms at work, by allocating, structuring, and coordinating resources at different levels of action $[19,20]$. Third, it underscores the importance of relational capabilities for the success of the IOR process [3, 7]. Thus, asset orchestration approach fosters better components identification as well as a greater understanding of the realized process by highlighting how the deeper shared processes and practices interrelate with the most tangible resources that lie beneath the surface, such as shared artefacts and vision $[34,36]$.

\section{Conceptual framework}

Two of the critical goals in an IOR context are first, to enable the process of sharing each partner's IT assets and identify a common business vision, and second, to translate these commonalities into shared processes and practices. In this regard, a process perspective provides a better understanding of the sequence of events as well as the specific mechanisms of the IOR process $[16,17]$.

Following the above line of thought, we propose that an IOR process implies on the one hand, that interorganizational collaborative efforts work well across organizational boundaries between business partners based on shared vision and IT artefacts. On the other hand, we posit that social interaction mechanisms fostering sharing knowledge about processes and practices that may emerge between decision makers, IT professionals, and users, should help in realizing an effective IOR.

This study aims at assessing how the reified structures and social dimensions of the IOR process affect each other. Specifically, social interactions can be illustrated as deep structures, recurring processes that lie under the surface structures [18]. The concept of deep structures is essential to a better understanding of the different levels of social systems [38]. Any organizational change, such as IOR will affect these patterns (i.e. processes and practices) and principles of interaction by imposing new and different set of rules and practices [38].

The changing business ecosystems and the advent of more open forms of collaboration [24] as well as an emerging concern about the practical usefulness of this research, encourages us to engage in a theorizing effort [39] based on a mechanism-based theorizing approach [4, 28]. Anchored in an open and network mode [5], the proposed conceptual framework illustrates an IOR process as a means to connect tangible resources (IT artefacts and vision) with intangible ones (processes and practices) through asset orchestration mechanisms that transform basic resources into more complex resources and activities [22].

In addition, the proposed conceptualization is based on the premise that asset orchestration mechanisms are distinguished by the different functions they fulfill at different levels of the firm activities $[12,19]$. As such, the identified allocating, structuring and coordinating mechanisms are based on cross-organizational boundaries knowledge sharing [14]. Moreover, due to the increasing information complexity at the organizational boundaries and the growing IT use between partners in an IOR context [5], we suggest that implementing the three mechanisms will result in an added value for the involved partners, especially with regard to their IT use.

An allocating resources mechanism is defined as the set of activities for using technological, financial, material and/or human resources in order to build value inside the firms and/or between partners [19, 40]. A structuring resources mechanism is related to grouping and assembling particular constellations of technological, financial, material and/or human resources inside the firms and/or between partners $[19,20]$. Finally, a coordinating resources mechanism refers to "managerial activities supporting assembling and reassembling firms complementary and co-specialized resources [19] (p. 25) [...] It also involves communication routines that allow to disseminate information and/or warn conflict between partners" (p. 73). In this line of thought, the IOR process reflects the progression of the jointly profit and the organizational cross-boundary mechanisms that are not bound by hierarchical and authority based relationships [5].

In addition to these specific mechanisms, we distinguish two categories of structures required to 
achieve an IOR process. First, the surface structures that are shaped in an evolutionary mode of change based on the variation, selection and retention processes [16], and where the partners' IT artefacts and vision are abandoned, modified or merged [31] in a mainly linear approach.

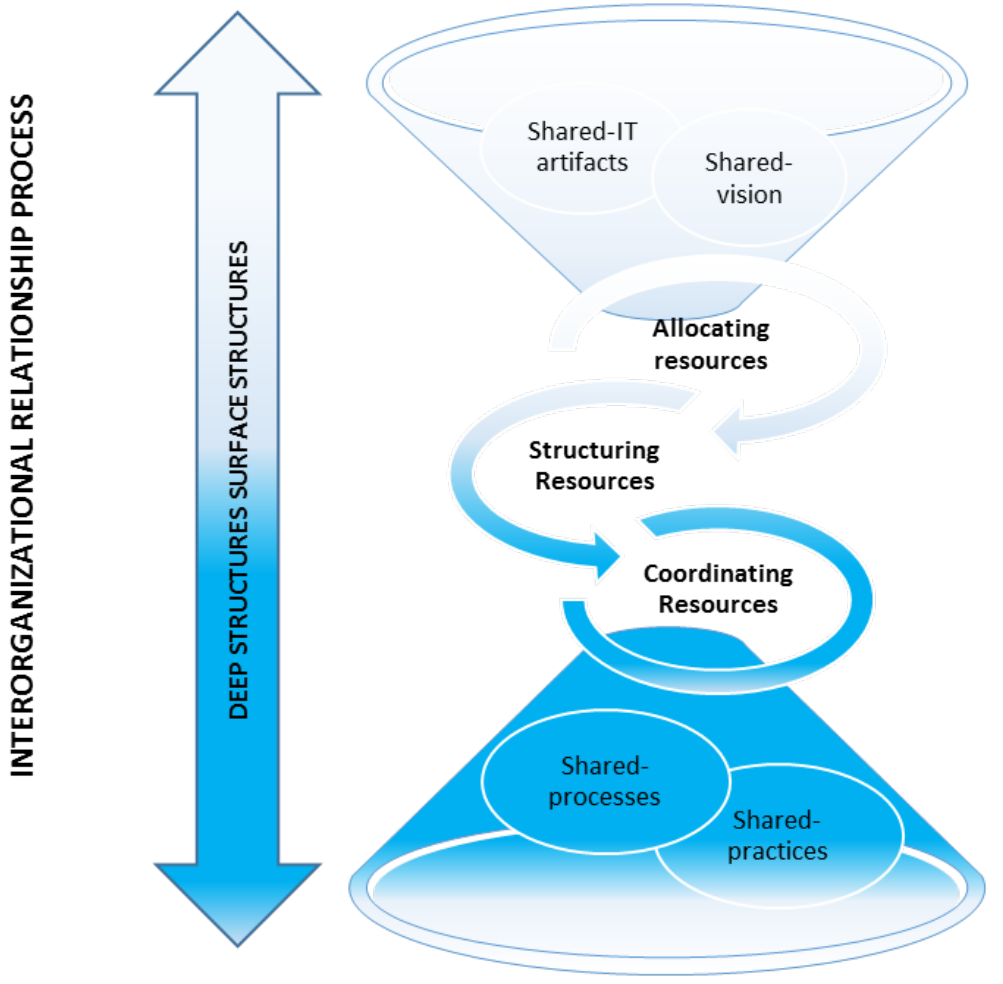

Figure 1. Conceptual framework

Second, the deep structures, which represent processes and practices that result from social and relational capabilities via recursive mechanisms of knowledge sharing [7, 16]. In other words, these structures reveal "a set of routines based on product technologies, process technologies, or broader business innovations as well as managerial activities" [14] (pp. 945-946) at different levels of interactions and managerial actions [5, 20]. Based on the above arguments, we suggest that the successful completion of an IOR process will be obtain from the continual adjustment between the surface and the deeper structures, through allocating, structuring and coordinating mechanisms.

\section{Methodology}

Adopting Siggelkow's (2007) view, the proposed framework (Figure 1) is the combined result of a conceptualization exercise as well as an empirical exposure, and is set to explore the specific mechanisms that are required to offer a better understanding of the complex phenomenon of an IOR. In this context, collaborating organizations are best outlined in a process of theorization that takes into consideration how decisions and actions at different levels of analysis shape each other [16, 17]. To do so, we adopt a qualitative research approach by using a single-case study method. This methodology is appropriate because it emphasizes the social construction as well as it reveals how our theorization operates in a particular context [41].

Theoretical sampling in case selection offers a number of advantages concerning the potential for discovery [42], the assessment of the framework internal logic as well as its usefulness in practice [21, 39]. In this regard, the selected case for this study had to provide particular conceptual insights about the asset orchestration mechanisms [43] as well as it had to support "causal" explanation approach of the IORs process [34, 42].

Respecting these criteria, the selected case was a Canadian SME that we will call CallCenter for reasons of confidentiality. Founded in 1999, the firm, a call center, offers specialized survey services, and other tailor-made automated solutions for marketing and commercial research applications to other enterprises. 
As an efficient way to gather rich empirical insights about the asset orchestration mechanisms dynamics in an IOR context [41], data were collected through semi-structured interviews that have been conducted with the owner-manager and the IT manager. Those two key-informants were met individually at four different times over a period of eight months for initial, complement, and validation interviews, for a total of about five hours. Transcriptions as well as the subsequent codification phase have been supported by NVivo software.

Adopting an abductive logic (inference to an explanation) [41], our analysis sought to identify the emerging asset orchestration mechanisms implemented by CallCenter to support its relationships with its main business partner ISSupplier (CallCenter's IS services supplier) as well as the dimensions of the surface and deep structures of the IOR. This was done by following a process analysis approach [21, 34], which relies on the sequencing of specific and cumulative mechanisms $[4,17]$.

\section{Case description}

Originally founded in an institutional context of a private Canadian college in 1999, CallCenter's activities were initially dedicated to support the practical component of an education program concerning customer service, through the exploitation of a training outbound call center. In 2003, this division of the institution was the object of an ownership transfer that has gradually led to a reorientation of its mission. Managed by its sole owner since then and reaching approximately 1 million outgoing calls a year, CallCenter has been growing steadily for about 10 years. The firm has now forty-five employees, mainly marketing agents, but also several supervisors, operations manager, IT manager as well as a technician analyst who combines IT and administration tasks.

Because of the long-standing business agreements dating back to the company inception, the shift from an educational training context to a private commercial research and marketing services (i.e. opinion polls, satisfaction measurement surveys and market studies) through telephone and web platforms has been completed in 2008 .

Since then and following major competitive and technological changes in this field of activities [44], the firm opened out its expertise in design and development of marketing analytical tools. This important shift was done by using an interactive voice response (IVR) platform which purpose is to allow fully automated communications, such as the confirmation of a delivery or circulation of largescale information provided by a public organization. Requiring an extensive knowledge-sharing across the organization as well as with its clients and other partners [45], IVR services were based on large volumes of data as well as automated and custommade application solutions.

Since 2010, there has been an increasing demand for those high-value services by companies in different sectors, such as banking, insurances, transport, and retail businesses. Moreover, because of the knowledge integration as well as the sophisticated architecture they require, these services also possessed a greater strategic value for all the involved partners [44].

In 2012, the revenues of CallCenter approached 3 million dollars, $70 \%$ of which came from its province clients. Combined with all of the above events, this meant that CallCenter was in need of a reorganization of its activities, including managerial, technological as well as relational structures.

In this regard, in the 2000s, ISSupplier has started to develop and support a set of survey software solutions for data collection in different languages, through different modes (phone, web, mobile, and interactive). As of January 2016, the company has offices in North America, Europe, and Australia and sells worldwide to over 500 companies. CallCenter's competitive environment is thus almost exclusively composed of large companies going thought major changes such as an increasing use of IT and other specialized software applications as well as the merging of different areas of intervention formerly independent (inbound / outbound call centers, web / phone survey services) [44].

Because of its size and language service distinction, CallCenter has always been considered as "a small player in the major leagues". However, far from being a disadvantage, these characteristics are rather strategic factors of distinction in a business niche as mentioned by CallCenter's owner:

"What makes our reputation is the speed with which we react, our facility to implement a project quickly."

With regard to the IOR process and in order to fulfill the stated strategic intent of "maximizing the use of our resources, human as well as technological", all of the above emphasize the importance for CallCenter of developing a set of asset orchestration mechanisms such as allocating, structuring and coordinating resources. 


\section{Case analysis}

\subsection{Allocating resources}

Initially motivated by economic considerations and the willingness to use the most common systems and technologies in the occupied market, the relationships between CallCenter and ISSupplier were first established based on technical grounds. In other words, until 2008, CallCenter maintained "activity-domain-based" relations with its systems supplier, within which it adopted, abandoned or modified its technology infrastructure at the whim of new versions and features offered by ISSupplier who sold the same products to all its other clients.

With a growing use of IT and the emergence of other specialized software applications, the needs for a greater management of the organizational assets was experienced by the entire business ecosystem [45]. Therefore, the shift toward more sophisticated services such as IVR somehow represented a milestone for CallCenter as well as for ISSupplier. Both firms were facing the need of a better orchestration of their respective organizational knowledge assets related to the IT artefacts as well as to the increasing outsourced activities within their industry. In this regard, CallCenter's owner was clear about the resources allocation he had to manage:

"I told you earlier how we like to solve complicated problems, such as IVR. However, at the beginning, we had to force the developer (ISSupplier) which presumably had a solution ready for such a thing ... We bought it and it was not functional. We then had to spend hundreds and hundreds of hours of programming to get to deliver [...]. But now, this is why several other polling firms use our services when they have questions about the programming of these tools... Moreover, we are now directly referred by the $R \& D$ people working for the developer (ISSupplier) who tell us how they are impressed with what we managed to do with their own tools".

According to the specific operational requirements in this field of activity [44], the mechanisms for resources allocation were also affected by higher IT investments as well as the implementation of security and control devices, in close collaboration with a third party specialized partner. Owning its technological infrastructure, CallCenter's hardware and software resources were updated as necessary and not based on a planned renewal schedule. For the owner, those resources as well as the knowledge that came from their increased use have enabled the firm "to detect opportunities and unaddressed needs."
According to Gilbert (2005), adequate resources allocation mechanism is a mean to overcome organizational inertia. This has been avoided thanks to the efforts that were put in place by CallCenter and ISSupplier.

\subsection{Structuring resources}

Starting with an evident bundle of shared IT artefacts acquired in a dominant transactional objective, the IOR process between CallCenter and ISSupplier began its evolution towards a more relational perspective in 2010 [15]. This change was needed when Web survey applications started to become the preferred choice compared to phonebased survey services. As mentioned by CallCenter's owner:

"This is not an application for the general public. [...] It is specific to our services. Few people have skills to use, adapt, and modify these applications to specific situations [that arise in our business ecosystem]. We must take advantage of this network and we must also be able to give support to others who are on the same technological platform as us [...] In addition to technical support from the company that develops and sells these systems, we often offer support on programming problems among polling firms".

This type of relationships is the first step in a collaboration that is going deeper than geographical or technological proximity $[4,46]$. In this regard, the growing collaboration that characterizes the relationship with ISSupplier is based on what is called 'organizational proximity' [47], and could not emerge without a similar business understanding and a shared vision about the quality of products and services that the two partners wanted to sell in a highly competitive and changing industry.

Our data analysis indicates also the presence of a structuring resources mechanism. Since 2011, CallCenter engaged in constant technological experimentation to combine and enhance its IT tools. Thus, the IT personnel transformed existing technological resources in a mode of creative and concrete learning-by-doing activities. The IT manager confirmed this situation:

"With the new software, there is an improved version for the automated calls, which I use in part. But I also use the older version, because with the new one, we cannot do everything and with the former either. Often, I make hybrid versions with both."

Illustrating how CallCenter and ISSupplier regularly combined their various resources to act beyond a simple customer-supplier exchange, CallCenter's owner specified how both firms were 
structuring their respective resources as well as they were coordinating some of their actions:

"In terms of technological infrastructure, we have everything we need. The challenge is mainly related to the organizational structure and management that follows."

As for the IT manager:

"We don't need more employees to do all this because we now have the technology to do what we need in an automated way."

\subsection{Coordinating resources}

With regard to the presence of a coordination mechanism, our analysis suggests that it is less about technical concerns than about communication activities. As CallCenter's owner describes:

"There are no silos of expertise; we do not have that mindset... [...] Because we are on the same technological platform, it is very easy to exchange projects. There is a lot of outsourcing activities that are done in our sector and this is much easier when you are on the same platform [...] There is a perfect continuity and a perfect control from the principal to the operating mandate."

In the same line of thought, according to CallCenter's owner, ISSupplier took advantage of the subsequent shared knowledge to develop new products and consolidate its advantage of being the most sought after systems in that growing market:

"They (ISSupplier) might treat us as a simple client, but they go beyond by referring us (CallCenter) to their international clients. Often, they will even invite us on mandates".

\subsection{From surface structures to deep structures}

Our study covered a period of 12 years (19992012), during which CallCenter and ISSupplier found common ground in terms of vision and IT-artefacts (surface structures) as well as processes and practices (deep structures). Representing milestones in the firm development and future success, the cumulative asset orchestration mechanisms at work between the two firms emphasize that to maintain their successful relationship, both partners must respectively allocate, structure and coordinate their resources [20,40]. This also means that when they were collaborating, CallCenter and ISSupplier were able to contribute to fostering systemic innovation that benefited the entire business ecosystem [19].

Thus, our data analysis revealed that the two partners developed specific competencies [3] based on shared knowledge and practices $[6,14]$. Anchored in relational and social structures, our case also illustrates how these firms mitigated the environmental change by developing co-specialized and complementary assets through a set of mechanisms [19] that allowed to create a jointly profit $[3,28]$. The data analysis suggests that in order to ensure the success of IOR, allocating and structuring resources mechanisms have to go beyond a simple explorative R\&D alliance [1].

\section{Conclusion and contributions}

The main contribution of a mechanism-based theorizing is to provide concrete tools for explanation [4]. In this regard, our single case study provides promising avenues concerning the role of a set of mechanisms that is required to orchestrate resources that led to specialized co-firm processes and practices $[19,20]$. The literature suggests that IORs are a complex process, because "structures, processes, and participants serve to influence and shape the various forms of governance in interorganizational relationships" [32] (p. 4). Yet, although research stresses the importance of the social challenges related to the IOR process [11], there is a paucity of studies that have examined the specific orchestration mechanisms in an alignment perspective of IT strategies, artefacts as well as processes achieved between different business partners.

We have focused on the relationship between the surface and deep structures of the IOR process by developing a conceptual framework based on the asset orchestration concept stemming from the extended-RBV perspective. The framework was used subsequently in an exploratory manner to analyze data from a case study. The results suggest that surface and deep structures are connected by three specific mechanisms (allocation, structuration, and coordination), which foster a better usage of each firm's resources as well as their shared resources.

Our exploratory study contributes in various ways. First, it adds to the body of literature on IOR by proposing a framework that provides a deeper understanding of a complex phenomenon, that is, the interorganizational relationships process. Second, while studies on strategic alliances became popular in recent years, surprisingly little is known about how social relationships and shared practices that emerge within these IOR and more importantly, how they affect the decisional process during an IOR. Our data analysis suggests that investigating the relationship between partners' shared vision and artefacts (surface structures) and shared processes and practices (deep structures) constitutes an important first step towards a better understanding of the IOR process. Third, our 
theorization work can be seen as a further encouragement to analyze emerging deep structures [18] with a process perspective $[17,34]$, in different interorganizational collaborative arrangements within which proximity refers to the whole organization as well as to the technological dimension for all the involved partners [47]. Finally, our framework has the potential to provide a foundation for developing empirical analyses of better understanding of the key challenges related to the development, implementation and success of IORs supported by IT-based applications.

For practitioners, our framework sheds light on the IOR process efforts. Thus, organizational crossboundary collaboration involves the negotiation of multiple domains of knowledge by the members of each partner firm who usually have a limited understanding of domains besides their own-shared domain of knowledge. While there are certainly other topics that could enlighten our understanding of IOR, we believe that differences in understandings of others' practices may have a significant impact on the process of IOR as well as other processes such as strategic alignment and IT governance.

While rich in insights about the nature of the relationship between surface and deep structures, the data from this single case study provided a preliminary support for our theorization. However, this exercise gave us evidence that using our conceptual framework may allow us to illuminate a complex phenomenon.

Our work opens avenues for future research such as conducting in-depth IOR multiple case studies to determine the extent of our conceptual framework's explanatory power and add to it.

\section{Acknowledgements}

The authors would like to gratefully acknowledge the FRQSC funding (no. 2015-NP-180713) received for this project.

\section{References}

[1] Albers, S., F. Wohlgezogen, and E.J. Zajac. "Strategic Alliance Structures: An Organization Design Perspective," Journal of Management, (42:3), 2016, pp. 582-614.

[2] Jin, L. and D. Robey. "Bridging Social and Technical Interfaces in Organizations: An Interpretive Analysis of Time-Space Distanciation," Information \& Organization, (18:3), 2008, pp. 177-204.

[3] Prasad, A. and P. Green. "On Information Technology Competencies for Collaborative Organizational Structures," Communications of the
Association for Information Systems, (38), 2016, pp. 379-399.

[4] Davis, G.F. and C. Marquis. "Prospects for Organization Theory in the Early Twenty-First Century: Institutional Fields and Mechanisms," Organization Science, (16:4), 2005, pp. 332-343.

[5] Gulati, R., P. Puranam, and M. Tushman. "MetaOrganization Design: Rethinking Design in Interorganizational and Community Contexts," Strategic Management Journal, (33:6), 2012, pp. 571-586.

[6] Loebbecke, C., P.C. van Fenema, and P. Powell. "Managing Inter-Organizational Knowledge Sharing," The Journal of Strategic Information Systems, (25:1), 2016, pp. 4-14.

[7] Markus, M.L., C.W. Steinfield, R.T. Wigand, and G. Minton. "Industry-Wide Information Systems Standardization as Collective Action: The Case of the U.S. Residential Mortgage Industry," MIS Quarterly, (30), 2006, pp. 439-465.

[8] Barringer, B.R. and J.S. Harrison. "Walking a Tightrope: Creating Value Through Interorganizational Relationships," Journal of Management, (26:3), 2000, pp. 367-403.

[9] Williams, C.K. and E. Karahanna. "Causal Explanation in the Coordinating Process: A Critical Realist Case Study of Federated IT Governance Structures," MIS Quarterly, (37:3), 2013, pp. 933964.

[10] Brown, C.V. "Horizontal Mechanisms Under Differing IS Organization Contexts," MIS Quarterly, (23:3), 1999, pp. 421-454.

[11] Robey, D., G. Im, and J.D. Wareham. "Theoretical Foundations of Empirical Research on Interorganizational Systems: Assessing Past Contributions and Guiding Future Directions," Journal of the Association for Information Systems, (9:9), 2008, pp. 497-518.

[12] Sirmon, D.G., M.A. Hitt, and R.D. Ireland. "Managing Firm Resources in Dynamic Environments to Create Value: Looking Inside the Black Box," Academy of Management Review, (32:1), 2007, pp. 273-292.

[13] Levina, N. "Collaborating on Multiparty Information Systems Development Projects: A Collective Reflection-In-Action View," Information Systems Research, (16:2), 2005, pp. 109-130.

[14] Maritan, C.A. and T.H. Brush. "Heterogeneity and Transferring Practices: Implementing Flow Manufacturing in Multiple Plants," Strategic Management Journal, (24:10), 2003, pp. 945-959.

[15] Prasad, A., P. Green, and J. Heales. "On IT Governance Structures and their Effectiveness in Collaborative Organizational Structures," International Journal of Accounting Information Systems, (13:3), 2012, pp. 199-220.

[16] Van de Ven, A.-H. and M.-S. Poole. "Explaining Development and Change in Organizations," Academy of Management Review, (20:3), 1995, pp. 510-540.

[17] Langley, A., Smallman, H. Tsoukas, and A.H. Van de Ven. "Process Studies of Change in Organization and 
Management: Unveiling Temporality, Activity, and Flow," Academy of Management Journal, (56:1), 2013, pp. 1-13.

[18] Heracleous, L. and M. Barrett. "Organizational Change as Discourse: Communicative Actions and Deep Structures in the Context of Information Technology Implementation," Academy of Management Journal, (44:4), 2001, pp. 755-778.

[19] Helfat, C.E., Finkelstein, S., Mitchell, W., Peteraf, M. A., Singh, H., Teece, D. J., and S. G. Winter. Dynamic Capabilities: Understanding Strategic Change in Organizations. 2007, Oxford, UK: Blackwell Publishing. 147 pages.

[20] Sirmon, D.G., Hitt, M. A., Ireland, R. D., and B. A. Gilbert. "Resource Orchestration to Create Competitive Advantage," Journal of Management, (37:5), 2011, pp. 1390-1412.

[21] Gross, N. "A Pragmatist Theory of Social Mechanisms," American Sociological Review, (74:3), 2009, pp. 358-379.

[22] Maritan, C.A. and M.A. Peteraf. "Building a Bridge Between Resource Acquisition and Resource Accumulation," Journal of Management, (37:5), 2011, pp. 1374-1389.

[23] Heide, J.B. "Interorganizational Governance in Marketing Channels," The Journal of Marketing, (58:1), 1994, pp. 71-85.

[24] Markus, M.L. and Q.N. Bui. "Going Concerns: The Governance of Interorganizational Coordination Hubs," Journal of Management Information Systems, (28:4), 2012, pp. 163-198.

[25] Oliver, C. "Determinants of Interorganizational Relationships: Integration and Future Directions," Academy of Management Review, (15:2), 1990, pp. 241-265.

[26] Lee, S. and G.G. Lim. "The Impact of Partnership Attributes on EDI Implementation Success," Information \& Management, (41:2), 2003, pp. 135148

[27] Lowndes, V. and C. Skelcher. "The Dynamics of Multi-Organizational Partnerships: An Analysis of Changing Modes of Governance," Public Administration, (76:2), 1998, pp. 313-333.

[28] Beimborn, D., F. Schlosser, and T. Weitzel. "Proposing a Theoretical Model for IT Governance and IT Business Alignment." in $42^{\text {nd }}$ Hawaii International Conference on System Sciences (HICSS). 2009. Hawaii, USA

[29] Chan, Y.E. "Why Haven't We Mastered Alignment? The Importance of the Informal Organization Structure," MIS Quarterly Executive, (1:2), 2002, pp. 97-112.

[30] Tanriverdi, H. and V.B. Uysal. "Cross-Business Information Technology Integration and Acquirer Value Creation in Corporate Mergers and Acquisitions," Information Systems Research, (22:4), 2011, pp. 703-720.

[31] Raymond, L., F. Bergeron, and A.-M. Croteau. "Innovation Capability and Performance of Manufacturing SMEs: The Paradoxical Effect of IT Integration," Journal of Organizational Computing and Electronic Commerce, (23:3), 2013, pp. 249-272.
[32] Croteau, A.-M. and F. Bergeron. "Interorganizational Governance of Information Technology." in $42^{\text {nd }}$ Hawaii International Conference on System Sciences (HICSS). 2009. Hawaii, USA.

[33] De Haes, S. and W. Van Grembergen. "IT Governance Structures, Processes and Relational Mechanisms: Achieving IT/Business Alignment in a Major Belgian Financial Group ". in $38^{\text {th }}$ Hawaii International Conference on System Sciences (HICSS), 2005. Hawaii, USA.

[34] Pentland, B.T. "Building Process Theory with Narrative: From Description to Explanation," Academy of Management Review, (24:4), 1999, pp. 711-724.

[35] Levina, N. and E. Vaast. "The Emergence of Boundary Spanning Competence in Practice: Implications for Implementation and Use of Information Systems," MIS Quarterly, (29:2), 2005, pp. 335-363.

[36] Gregor, S. "The Nature of Theory in Information Systems," MIS Quarterly, (30:3), 2006, pp. 611-642.

[37] Barney, J.B., D.J. Ketchen, and M. Wright. "The Future of Resource-Based Theory," Journal of Management, (37:5), 2011, pp. 1299-1315.

[38] Gersick, C.J. "Revolutionary Change Theories: A Multilevel Exploration of the Punctuated Equilibrium Paradigm," Academy of Management Review, (16:1), 1991, pp. 10-36.

[39] Rivard, S. "Editor's Comments: The Ions of Theory Construction," MIS Quarterly, (38:2), 2014, pp. iiixiii.

[40] Gilbert, C.G. "Unbundling the Structure of Inertia: Resource versus Routine Rigidity," Academy of Management Journal, (48:5), 2005, pp. 741-763.

[41] Eisenhardt, K.M. and M.E. Graebner. "Theory Building from Cases: Opportunities And Challenges," Academy of Management Journal, (50:1), 2007, pp. 25-32.

[42] Yin, R.K., Case Study Research Design and Methods. $4^{\text {th }}$ ed. 2009, Thousand Oaks: Sage. 219 pages.

[43] Siggelkow, N. "Persuasion with Case Studies," Academy of management journal, (50:1), 2007, pp. 20-24.

[44] Jack, E.P., T.A. Bedics, and C.E. McCary. "Operational Challenges in the Call Center Industry: A Case Study and Resource-Based Framework," Managing Service Quality, (16:5), 2006, pp. 477-500.

[45] Chou, T.C. "Exploring Call Center-Enabled Organizational Mechanisms Associated with Combinative Capabilities," Management Decision, (49:6), 2011, pp. 841-859.

[46] Croteau, A.-M., P.-M. Léger, and L. Cassivi. "The Role of Life Cycle Concepts in the Assessment of Interorganizational Alignment," Industrial Management \& Data Systems, (108:2), 2008, pp. 145-161.

[47] Knoben, J. and L.A.G. Oerlemans. "Proximity and Inter-Organizational Collaboration: A Literature Review," International Journal of Management Reviews, (8:2), 2006, pp. 71-89. 